\title{
Carboxymethyl- $\beta$-glucan/chitosan nanoparticles: new thermostable and efficient carriers for antigen delivery
}

\author{
Ana Sara Cordeiro ${ }^{1,4} \cdot$ Yagmur Farsakoglu $^{2,5}$. José Crecente-Campo ${ }^{1}$ María de la Fuente ${ }^{3}$. Santiago F. González ${ }^{2}$. \\ María José Alonso ${ }^{1}$ [D
}

Accepted: 22 March 2021 / Published online: 1 April 2021

(c) Controlled Release Society 2021

\begin{abstract}
In the last few decades, nanotechnology has emerged as an important tool aimed at enhancing the immune response against modern antigens. Nanocarriers designed specifically for this purpose have been shown to provide protection, stability, and controlled release properties to proteins, peptides, and polynucleotide-based antigens. Polysaccharides are particularly interesting biomaterials for the construction of these nanocarriers given their wide distribution among pathogens, which facilitates their recognition by antigen-presenting cells (APCs). In this work, we focused on an immunostimulant beta-glucan derivative, carboxymethyl- $\beta$-glucan, to prepare a novel nanocarrier in combination with chitosan. The resulting carboxymethyl- $\beta$-glucan/ chitosan nanoparticles exhibited adequate physicochemical properties and an important protein association efficiency, with ovalbumin as a model compound. Moreover, thermostability was achieved through the optimization of a lyophilized form of the antigen-loaded nanoparticles, which remained stable for up to 1 month at $40^{\circ} \mathrm{C}$. Biodistribution studies in mice showed an efficient drainage of the nanoparticles to the nearest lymph node following subcutaneous injection, and a significant colocalization with dendritic cells. Additionally, subcutaneous immunization of mice with a single dose of the ovalbumin-loaded nanoparticles led to induced $\mathrm{T}$ cell proliferation and antibody responses, comparable to those achieved with alum-adsorbed ovalbumin. These results illustrate the potential of these novel nanocarriers in vaccination.
\end{abstract}

Keywords Nanovaccines · Carboxymethyl- $\beta$-glucan · Chitosan · Biodistribution · Two-photon microscopy $\cdot$ Immunization

Santiago F. González

santiago.gonzalez@irb.usi.ch

$\triangle$ María José Alonso

mariaj.alonso@usc.es

1 Center for Research in Molecular Medicine \& Chronic Diseases (CIMUS), School of Pharmacy, Health Research Institute of Santiago de Compostela (IDIS), Universidade de Santiago de Compostela, Campus Vida, Santiago de Compostela 15706, Spain

2 Institute for Research in Biomedicine, Università Della Svizzera Italiana, via Vincenzo Vela 6, Bellinzona 6500, Switzerland

3 Nano-Oncology and Translational Therapeutics Unit, Health Research Institute of Santiago de Compostela (IDIS), Clinical University Hospital of Santiago de Compostela (CHUS), Santiago de Compostela 15706, Spain

4 Leicester School of Pharmacy, De Montfort University, The Gateway, Leicester LE1 9BH, UK

5 NOMIS Center for Immunobiology and Microbial Pathogenesis, The Salk Institute for Biological Studies, La Jolla, CA, USA

\section{Introduction}

In the last decades, vaccine research has been mainly focused in developing safer antigens and designing more efficient adjuvants. The first ones, including purified proteins and synthetic peptides, are expected to show reduced side effects, but are also likely to be less immunogenic [1, 2]. Similarly, DNA and RNA vaccines including the ones most recently under development for SARS-CoV-2 require delivery systems to enable efficient presentation of the antigenic genetic material to the appropriate immune cells [3]. For this reason, adjuvant research has been one of the leading paths to efficient modern vaccines. Currently, marketed vaccine formulations incorporate either aluminium salts (also known as alum) or lipid-based adjuvants, including squalene emulsions (e.g., AS03 and MF59), liposome formulations (AS01), as well as a combination of alum and an immunostimulatory lipid, commercially available as AS04 [4]. Particulate-based adjuvants are gaining increasing attention in the field, with formulations containing polymeric and lipid-based micro- and nanoparticles 
currently under clinical development [4-6]. These carriers are very suitable for antigen delivery, providing protection against degradation, controlled delivery and favoring recognition by antigen-presenting cells (APCs). Additionally, particulate carriers can also be designed to incorporate molecular adjuvants in their structure, to enhance the immune response achieved $[7,8]$.

Since the development of the first polymeric antigen carriers in the 70s [9], many authors have contributed to the expansion of this research field. Polysaccharides are particularly attractive in this scope, with structural patterns similar to those of bacteria and virus, which facilitate their recognition by the immune cells $[10,11]$. Among these, chitosan (CS) has played a significant role in this field. For example, our group has shown the potential of CS-based nanocarriers for antigen delivery, generating high and long-lasting immune responses in animal models against encapsulated antigens such as tetanus toxoid, rHBsAg, and a candidate vaccine against HIV [12-17].

On the other hand, beta glucans are a class of polysaccharides usually found in the cell wall of several microorganisms, and have emerged as promising immunostimulants [18-20]. More specifically, these polymers have been described to interact with immune cells through the complement receptor 3 (CR3) and the Dectin-1 receptor [21, 22]. Based on these properties, some authors proposed the use of hollow beta glucan natural microparticles, obtained from emptying the cell content of Saccharomyces cerevisae, as antigen delivery carriers [23-27]. Despite the interest of this approach, these natural particles do intrinsically exhibit a variability in their physicochemical properties and, possibly, in their interaction with the immune cells $[28,29]$. Other authors have preferred the use of isolated natural or synthetic beta glucans as starting materials for the preparation of nanoparticles loaded with antigens and immunostimulants [30, 31]. However, this technological approach is still in an early stage.

Based on this information, our objective of this work was the development of carboxymethyl- $\beta$-glucan $(\mathrm{CM} \beta \mathrm{G})$ nanoparticles in combination with CS. To evaluate the potential of these nanocarriers for antigen delivery, we used ovalbumin (OVA) as a model antigen associated to the nanoparticles. We performed in vivo biodistribution studies upon subcutaneous administration of the OVA-loaded carriers in order to study their specific interaction with immune cells. Finally, we analyzed the immune response elicited by the antigen-loaded polysaccharide-based nanoparticles in a mice model.

\section{Materials and methods}

\section{Materials}

Pharmaceutical grade chitosan hydrochloride, with a molecular weight of $47 \mathrm{kDa}$ and an $80-95 \%$ deacetylation degree, was acquired from Heppe Medical Chitosan GmbH (Halle, Germany). Carboxymethyl- $\beta$-glucan, obtained from Saccharomyces cerevisae and modified with carboxymethyl groups at an $85 \%$ substitution degree, was a kind donation from Mibelle AG Biochemistry (Buchs, Switzerland). Ovalbumin, in the form of complete protein with a molecular weight of $45 \mathrm{kDa}$, was provided by Invivogen (Toulouse, France). 5-Carboxytetramethyl-rhodamine succinimidyl ester (5-TAMRA SE) was acquired from emp Biotech GmbH (Berlin, Germany). Sucrose dilaureate (Surfhope ${ }^{\circledR}$ D1216) was obtained from Mitsubishi-Chemical Foods Corporation (Tokyo, Japan). Sucrose was bought from Acofarma (Madrid, Spain) and trehalose (pharmaceutical grade) from Pfanstiehl (Waukegan (IL), USA). Polyvinyl pyrrolidone (PVP, Kollidon ${ }^{\circledR} 25$ ) was purchased from BASF (Ludwigshafen, Germany). Squalene was acquired from Merck Millipore (Darmstadt, Germany). Sorbitan monooleate ( $\operatorname{Span}^{\circledR} 80$ ), bovine serum albumine, and glycine were obtained from Sigma-Aldrich (Saint Louis, USA). All solvents were of HPLC grade, supplied by Thermo Fisher Scientific (Waltham, USA) or Scharlab SL (Barcelona, Spain).

\section{Preparation and characterization of CS:CM $\beta$ G nanoparticles}

Nanoparticles were prepared at three different chitosan: carboxymethyl- $\beta$-glucan (CS:CM $\beta G)$ mass ratios $(2: 1,4: 1$, and 1:2), after addition of an aqueous solution of $\mathrm{CM} \beta \mathrm{G}$ in ultrapure water $(2 \mathrm{mg} / \mathrm{mL}, 1 \mathrm{~mL})$ over an aqueous solution of CS in acetate buffer $10 \mathrm{mM}, \mathrm{pH} 5.5(4 \mathrm{mg} / \mathrm{mL}, 1 \mathrm{~mL})$, under magnetic stirring for $5 \mathrm{~min}$ at room temperature (RT).

\section{Particle size, surface charge, and polydispersity index}

The main physicochemical characteristics of the nanoparticles, particle size, surface charge, and polydispersity index $(\mathrm{PdI})$, were determined at RT, after proper dilution in ultrapure water or aqueous solution of $\mathrm{KCl}(1 \mathrm{mM})$ (for zeta potential). Particle size and PdI were determined by photon correlation spectroscopy (PCS), and zeta potential was measured by laser Doppler anemometry (LDA) (Zetasizer NanoZS ${ }^{\circledR}$, Malvern Instruments; Malvern, UK).

\section{Yield of production and elemental analysis}

Nanoparticles were isolated by centrifugation at $15,000 \times g$ for $30 \mathrm{~min}$ at $15{ }^{\circ} \mathrm{C}$ (Hettich Universal $32 \mathrm{R}$; Tuttlingen, Germany). The pellets obtained after separation were freezedried (Genesis SQ freeze-drier; Virtis, USA) and weighed after this process. Production yield was determined according to the following equation (Eq. 1): 
Yield $(\%)=\frac{\text { Freeze }- \text { dried nanoparticle weight }}{\text { Theoretical total solids weight }} \times 100$

For elemental analysis, nanoparticles before and after isolation by centrifugation were freeze-dried and analyzed for their content in carbon, oxygen, and nitrogen (Finnigan FLASH EA 1112; Thermo Scientific, Waltham (MA), USA), with the nitrogen being specific for CS and therefore allowing differentiation between both polymers. Solutions of the starting polymers, $\mathrm{CS}$ and $\mathrm{CM} \beta \mathrm{G}$, were also freeze-dried and analyzed as controls.

\section{Preparation of fluorescent CS:CM $\beta$ G nanoparticles}

For the preparation of fluorescently labelled nanoparticles, CS was previously conjugated with the marker 5-carboxytetramethylrhodamine NHS ester, single isomer (5-TAMRA-SE). For this purpose, $100 \mu \mathrm{L}$ of a $10 \mathrm{mg} / \mathrm{mL}$ solution of TAMRA in DMSO were added to $1 \mathrm{~mL}$ of a solution of CS at $10 \mathrm{mg} / \mathrm{mL}$ in acetate buffer $10 \mathrm{mM}$ (pH 5.5), under magnetic stirring. The reaction was kept at RT in dark for $1 \mathrm{~h}$. The resultant solution was dialyzed for $24 \mathrm{~h}$ against sodium chloride $(50 \mathrm{mM})$ and then for $24 \mathrm{~h}$ against ultrapure water. Finally, the labelled CS solution was recovered from the dialysis membrane and set to a final CS concentration of $5 \mathrm{mg} / \mathrm{mL}$. Fluorescent particles were prepared as described in the "Preparation and characterization of CS:CM $\beta$ G nanoparticles" section, using for this purpose a physical mixture of plain CS and TAMRA-labelled CS (3:1 mass ratio).

\section{Association of OVA}

Encapsulation of ovalbumin (OVA) was achieved by mixing $40 \mu \mathrm{L}$ of an aqueous solution of the protein $(10 \mathrm{mg} / \mathrm{mL})$ with $1 \mathrm{~mL}$ of the anionic solution of CM $\beta \mathrm{G}(2 \mathrm{mg} / \mathrm{mL})$, and subsequent addition of this phase to $1 \mathrm{~mL}$ of CS solution $(4 \mathrm{mg} / \mathrm{mL})$ under magnetic stirring for $5 \mathrm{~min}$. Nanoparticles were isolated and characterized as described previously ("Particle size, surface charge, and polydispersity index" section). Fluorescent OVA-loaded nanoparticles were also prepared using this procedure.

To determine the association efficiency of the model antigen, OVA-loaded CS:CM $\beta$ G nanoparticles (OVA-NP) were centrifuged for $30 \mathrm{~min}$ at $15,000 \times g$ (Hettich Universal $32 \mathrm{R}$; Tuttlingen, Germany) at $15^{\circ} \mathrm{C}$ on a glycerol bed. Supernatants were collected and free ovalbumin was quantified through linearized Bradford protein assay [32], against a calibration curve prepared with the supernatant of blank nanoparticles. Protein absorbance was measured at $620 \mathrm{~nm}$ and $450 \mathrm{~nm}$ (Multiskan ${ }^{\mathrm{TM}}$ FC Microplate Photometer, Thermo Fisher Scientific; Waltham (MA), USA) and the ratio between those values was used to calculate the concentration in the samples. The loading capacity of the OVA-NP was also calculated according to the following equation (Eq. 2):

Loading capacity $(\%)=\frac{(\text { Association efficiency }) \times(\text { Theoretical OVA weight })}{(\text { Yield }) \times(\text { Total polymers weight })} \times 100$

The stability of the antigen after its inclusion in the nanoparticles was further assessed by fluorescence Western blot. Briefly, OVA-NPs were incubated with a reducing sample buffer containing $\beta$-mercaptoethanol for $5 \mathrm{~min}$ at $95^{\circ} \mathrm{C}$. Then, samples were loaded on a 10\% SDS-PAGE gel and proteins were separated by electrophoresis at room temperature (RT) for $1 \mathrm{~h}$. Proteins were then transferred to a PVDF membrane (Immobilon-FL ${ }^{\circledR}$, Merck Millipore; Darmstadt, Germany) for $90 \mathrm{~min}$, and the membranes were subsequently blocked with SEA BLOCK blocking buffer (Thermo Fisher Scientific; Waltham (MA), USA) for $2 \mathrm{~h}$ at RT. Finally, the membranes were incubated overnight at $4{ }^{\circ} \mathrm{C}$ with a primary rabbit polyclonal anti-ovalbumin antibody (abcam; Cambridge, UK) (dilution 1:2000), washed extensively and then $1 \mathrm{~h}$ at RT with a secondary donkey anti-rabbit IgG antibody, labelled with Alexa Fluor ${ }^{\circledR} 680$ (abcam; Cambridge, UK) (dilution 1:10,000). Detection of protein fluorescence was performed with an Odyssey Infrared Imaging System (LICOR, Lincoln (NE), USA).

\section{Morphological characterization}

The morphology of OVA-NP was evaluated by transmission electron microscopy (TEM). Nanoparticles were placed on Formvar-coated copper grids and stained with 2\% (w/v) phosphotungstic acid (Sigma-Aldrich; Saint Louis, USA). Following an overnight drying step, at room temperature, the samples were observed with a JEM-2010 TEM equipment (JEOL; Peabody (MA), USA).

\section{Stability studies}

The stability of the nanoparticles in storage $\left(4{ }^{\circ} \mathrm{C}\right)$ was evaluated through the control of the colloidal properties of the nanoparticles during time. For this purpose, at the determined time points, samples of the isolated nanoparticles were collected to measure particle size and PdI, as described in the "Particle size, surface charge, and polydispersity index" section.

\section{Freeze-drying of OVA-loaded CS:CM $\beta$ G nanoparticles}

A powder form of OVA-NP was obtained through freezedrying in the presence of cryoprotectant. A screening comparing different cryoprotectants (5\% sucrose, $5 \%$ trehalose, $5 \%$ polyvinyl pyrrolidone (PVP) and a mixture of $0.24 \%$ 
glycine $+1.2 \%$ sucrose) and initial nanoparticle concentrations ( 1.5 and $3 \mathrm{mg} / \mathrm{mL}$ ) was performed. The $\mathrm{NP}$ were frozen overnight at $-20{ }^{\circ} \mathrm{C}$ and lyophilized in a VirTis Genesis 25L equipment (Model SQ EL-85, SP Scientific; Warminster (PA), USA). Initial freezing temperature was $-30{ }^{\circ} \mathrm{C}$, and the drying process lasted a total of $46 \mathrm{~h}$, divided in two steps. The samples were then recovered to initial nanoparticle concentration adding ultrapure water and vortex agitation until complete resuspension. Characterization of the nanoparticle suspensions after freeze-drying was performed as described in the "Particle size, surface charge, and polydispersity index" section. The integrity of the antigen after this process was also evaluated by Western blot, as described in the "Association of OVA" section.

\section{Stability of freeze-dried formulations}

Freeze-dried samples of the formulations described in the previous section were kept in controlled temperature and humidity conditions, namely at $25^{\circ} \mathrm{C} / 60 \%$ humidity and at $40{ }^{\circ} \mathrm{C} / 75 \%$ humidity in accordance with the guidelines for accelerated stability testing of drug delivery formulations [33]. At pre-determined time-points, the formulations were resuspended to the initial concentration with ultrapure water and vortex agitation. Following, the formulations were characterized as described in the "Particle size, surface charge, and polydispersity index" and "Association of OVA" sections for their physicochemical properties and for antigen integrity, respectively.

\section{In vivo evaluation of the lymphatic biodistribution and immune response generated by CS:CM $\beta \mathrm{G}$ nanoparticles}

C57/BL6 female 6-8-week-old mice, bred in-house or acquired from Janvier labs (Le Genest-Saint-Isle, France), were used for in vivo experiments. Separate groups of animals were used for biodistribution and immunization studies. Animals were kept in specific pathogen-free facilities at Institute for Research in Biomedicine (Bellinzona, Switzerland) with food and water ad libitum. All experiments complied with the Swiss Federal Veterinary Office guidelines and the veterinarian local authorities approved animal protocols.

\section{Biodistribution in the lymphatic system}

Administration schedule Five microliters of blank or OVANP ( $2 \mu \mathrm{g}$ of OVA), were diluted with $7.5 \mu \mathrm{L}$ of PBS and administered to mice through a single-dose injection in the footpad. Fifteen to $20 \mathrm{~min}$ after this injection, $0.5 \mu \mathrm{g}$ of CD169-Alexa Fluor ${ }^{\circledR} 647$ and CD21/35-Pacific Blue, were also injected in both footpads in a final volume of PBS of 5 $\mu \mathrm{L}$, to adequately label different cell types. Polystyrene nanoparticles of $200 \mathrm{~nm}$ labelled in green (Firefli ${ }^{\mathrm{TM}}$ Fluorescent Green) were co-injected with the nanoparticles, to normalize the results.

Ex vivo lymph node imaging Popliteal and lumbar lymph nodes (LN) of the injected mice were harvested at $12 \mathrm{~h}$ postinjection and kept in PBS at $4{ }^{\circ} \mathrm{C}$. As a control, one axillary lymph node was also collected at the same time point. Imaging was performed with a customized two-photon platform (TrimScope, LaVision BioTec GmbH; Bielefeld, Germany). Two-photon excitation of the fluorescent markers and tissue second harmonic generation (SHG) were acquired using two tunable Ti:Sapphire lasers (Chamaleon Ultra I, Chamaleon Ultra II, Coherent Inc.; Santa Clara (CA), USA) with an output wavelength in the range of 690-1080 nm. Additionally, an optical parametric oscillator emitting in the range of 1010 to $1340 \mathrm{~nm}$ (Chamaleon Compact OPO, Coherent Inc.; Santa Clara (CA), USA) was also used as part of the system. 3D reconstruction of the $\mathrm{LN}$ was performed with a Nikon Plan Apo $\lambda 10 X / 0.45$ objective, with a mosaic of up to $4 \times 3$ adjacent field-of-view image acquisitions.

Image analysis Mosaic images obtained by two-photon microscopy were reconstructed using FIJI software [37], with an automated image processing custom-developed script. The hyperstacks were then loaded on Imaris 7.7.2 (Bitplane; Zurich, Switzerland) software to obtain the 3D rendering of the LN. Throughout each experiment, fluorescence intensity obtained for each channel was fixed in a range and quantified using the Imaris software to create individualized surfaces, corresponding roughly to particles or agglomerates.

Flow cytometry The LN, previously collected for imaging, were disrupted with tweezers and digested for $10 \mathrm{~min}$ at $37{ }^{\circ} \mathrm{C}$ in an enzyme mix containing: DNase I [0.28 mg/ $\mathrm{ml}$ (Amresco; Solon (OH), USA); dispase [1 U/ml] (Corning; New York City (NY), USA) and collagenase P [0.5 mg/ml] (Roche; Basel, Switzerland) in calcium- and magnesium-free PBS (PBS-) (Sigma-Aldrich; Saint Louis (MO), USA). Subsequently, the reaction was stopped with a solution of $2 \mathrm{mM}$ EDTA (Sigma-Aldrich; Saint Louis (MO), USA) and 2\% heat-inactivated filter-sterilized Fetal Bovine Serum (Thermo Fisher Scientific; Waltham (MA), USA) in PBS-. Different cell populations were stained using labelled antibodies [ $\alpha$ MHCII (M5/114.15.2), $\alpha \mathrm{CD} 11 \mathrm{c}(\mathrm{N} 418), \alpha \mathrm{CD} 11 \mathrm{~b}(\mathrm{M} 1 / 70), \alpha \mathrm{CD} 80$ (16-10A1), $\alpha \mathrm{CD} 86$ (GL-1)] (BioLegend, San Diego (CA), USA) and the samples were analyzed by flow cytometry on LSRF ortessa $^{\mathrm{TM}}$ (BD Biosciences; San Jose (CA), USA). Data were analyzed with FlowJo ${ }^{\circledR}$ software (FlowJo, LLC; Ashland (OR), USA). 
Immune response T-cell priming To understand the outcome of the developed nanocarriers in antigen delivery and effective immune system triggering, we designed an in vivo T-cell priming assay. For this purpose, the spleen from an OT-II HZ mouse was collected and processed to obtain a single cell suspension. $\mathrm{CD}^{+} \mathrm{T}$ cells were subsequently isolated using a specific EasySep ${ }^{\mathrm{TM}}$ isolation kit, according to manufacturer's instructions (STEMCELL Technologies; Vancouver, Canada). Approximately $4.8 \times 10^{6}$ cells were obtained and stained with CFSE (Invitrogen ${ }^{\mathrm{TM}}$, Thermo Fisher Scientific; Waltham (MA), USA) at $0.5 \mu \mathrm{M}$ in $2 \mathrm{~mL}$ PBS-, through incubation for $20 \mathrm{~min}$ at $37{ }^{\circ} \mathrm{C}$. After staining, excess dye was removed by an additional incubation with FBS-supplemented PBS for 5 min. Finally, $\mathrm{CD} 4^{+} \mathrm{T}$ cells were washed and resuspended in PBS- in a total volume of $600 \mu \mathrm{L}$.

Approximately $8 \times 10^{5}$ CFSE-labelled CD45.1 OTII transgenic $\mathrm{T}$ cells were intravenously injected to two C57/ BL6 recipient mice in a total volume of $100 \mu \mathrm{L}$ (in PBS-). Twenty-four hours later, these mice received $15 \mu \mathrm{L}$ of OVANP ( $20 \mu \mathrm{g}$ of OVA) or alum-adsorbed OVA (10 $\mu \mathrm{g}$ of OVA $)$ subcutaneously in each footpad. For alum-adsorbed OVA, $10 \mu \mathrm{L}$ endotoxin-free OVA (Endograde ${ }^{\mathrm{TM}}$ OVA $1 \mathrm{mg} / \mathrm{mL}$; Profos AG; Regensburg, Germany) were mixed with $5 \mu \mathrm{L}$ of alum $(10 \mu \mathrm{g} / \mathrm{mL}$; Thermo Fisher Scientific; Waltham (MA), USA). After three days, popliteal lymph nodes were harvested, and single cell suspensions were obtained. Finally, cells were stained with the priming panel $(0.1 \mu \mathrm{g}$ CD 45.1 PerCP Cy5.5 and 0.2 $\mu \mathrm{g}$ CD4 APC/Cy7) (BioLegend; San Diego (CA), USA) for 30 min on ice, for further cytometry analysis.

\section{Antibody and antibody-secreting cell quantification C57/} BL6 mice were divided into three treatment groups $(n=3$ each), receiving either $20 \mu \mathrm{g}$ of OVA loaded in OVA-NP or the appropriate controls (OVA in solution and alumadsorbed OVA) by subcutaneous injection. Serum levels of $\mathrm{IgG}$ antibodies generated following immunization of these mice were determined using an ELISA method. For this purpose, blood from immunized mice was collected at day 10 post-immunization, allowed to clot at $4{ }^{\circ} \mathrm{C}$ for $30 \mathrm{~min}$ and centrifuged at $2000 \times g$ for $10 \mathrm{~min}$ at $4{ }^{\circ} \mathrm{C}$ to obtain serum. These samples were stored at $4{ }^{\circ} \mathrm{C}$ until assayed. According to the technique, 96-well flat-bottom $\mathrm{Nunc}^{\mathrm{TM}}$ microplates (Thermo Fisher Scientific; Waltham (MA), USA) were coated overnight with ovalbumin $(1 \mathrm{mg} / \mathrm{mL})$ at $4{ }^{\circ} \mathrm{C}$ and the wells were subsequently blocked with $1 \%$ bovine serum albumin (BSA) in PBS for $1 \mathrm{~h}$ at RT. Then, serial dilutions of the sera samples in $1 \%$ BSA were added to each well and incubated for $1 \mathrm{~h}$ at RT. After washing, the plates were incubated with a biotin-conjugated $\alpha$-IgG antibody (SouthernBiotech; Birmingham (AL), USA) for $1 \mathrm{~h}$ at RT. After washing the primary antibody, the plate was incubated with streptavidin-conjugated horseradish peroxidase (HRP) (Sigma-Aldrich; Saint Louis, USA) for $30 \mathrm{~min}$ at RT. The assay was developed using 3,3',5,5'-tetramethylbenzidine (TMB) substrate (Merck Millipore, Burlington (MA), USA). Antibody titers were calculated from the absorbance measured at $450 \mathrm{~nm}$ for the chromogen produced in this reaction, using a microplate reader (BioTek PowerWave HT 340; BioTek, Winooski (VT), USA).

For the quantification of antibody-secreting cells (ASC) levels elicited by these immunization approaches, we used an enzyme-linked immunospot assay (ELISPOT). On day 10 post-immunization, popliteal LN were aseptically removed from the mice, disrupted, and passed through a 40-mm cell strainer. Cells $\left(4 \times 10^{5}\right)$ were plated on OVA-coated $(1 \mathrm{mg} /$ $\mathrm{mL}$ ) filter plates (MultiScreen ${ }^{\circledR}$ HTS) (Merck Millipore; Burlington (MA), USA) and incubated for $16 \mathrm{~h}$ at $37{ }^{\circ} \mathrm{C}$. For detection, a biotin-conjugated $\alpha$-IgG or $\alpha$-IgM antibody (SouthernBiotech; Birmingham (AL), USA) was used, followed by streptavidin-conjugated HRP (Sigma-Aldrich; Saint Louis, USA). A developing solution consisting of $200 \mathrm{~mL}$ 3-amino-9-ethylcarbazole (AEC) solution (SigmaAldrich; Saint Louis, USA) in $9 \mathrm{~mL}$ sodium acetate buffer containing $4 \mathrm{~mL} 30 \% \mathrm{H}_{2} \mathrm{O}_{2}$ was subsequently added. Spots were visualized on a CTL ELISPOT reader using ImmunoSpot 5.1 software (Cellular Technology Limited; Cleveland $(\mathrm{OH}), \mathrm{USA})$.

\section{Statistical analysis}

Statistical analysis, as well as data graphs, were obtained using Prism 7 (GraphPad Software; La Jolla (CA), USA). Unpaired $t$ test with Welch's correction was used to analyze the biodistribution results, while Kruskal-Wallis test with Dunn's multiple comparisons test was applied in the immune response data. In both cases, statistical significance was defined as * $(p<0.05), * *(p<0.01),{ }^{* * *}(p<0.001)$, and $* * * *(p<0.0001)$.

\section{Results and discussion}

In this work, we selected beta glucans as biomaterials for the design of new antigen carriers based on their reported immunomodulatory properties $[10,11,21,22]$. Some groups focused on the use of hollow glucan particles, obtained from chemical treatment of the yeast particles and loaded with different antigens [23-27]. However, these particles, being directly derived from nature, are intrinsically variable and this variability may be translated into their interaction with the immune system. Other authors have chosen a synthetic approach to prepare glucan micro and nanoparticles containing antigens in addition to $\mathrm{CpG}$ oligonucleotides (adjuvant) [30, 31, 34-36]. The results obtained in vivo have shown 
their capacity to stimulate an immune response against several antigens.

Considering these previous results, we aimed to develop a new nanocarrier prototype combining $\mathrm{CM} \beta \mathrm{G}$, of anionic nature with the cationic polysaccharide chitosan. The selected beta glucan derivative was recently evaluated by our group as a coating in polymeric nanocapsules, which have shown promising biodistribution to the lymphatic system and high accumulation in lymph nodes following subcutaneous administration to mice [37]. On the other hand, the adjuvant potential of chitosan, particularly when used in the form of nanoparticles, was first demonstrated by our group in the late 90s [38] and has been since explored in the group for immunization against various infectious agents [12, 14-17]. Using OVA as a model antigen, we studied the interaction of antigen-loaded nanoparticles with immune cells, their access to the lymph nodes after subcutaneous injection to mice, and their efficacy in delivering OVA to the immune cells and in eliciting an immune response after a single-dose subcutaneous administration.

\section{Development and optimization of CS:CM $\beta$ G nanoparticles}

\section{Preparation of blank nanoparticles}

Nanoparticles were formed by electrostatic interaction between the anionic $\mathrm{CM} \beta \mathrm{G}$ and the cationic CS, as previously reported for the preparation of other polysaccharidebased nanoparticles [39-41]. The pH of the CS solution was adjusted to 5.5 with acetate buffer $10 \mathrm{mM}$, and the $\mathrm{pH}$ of the $\mathrm{CM} \beta \mathrm{G}$ solution was kept unchanged, at around $\mathrm{pH}$ 7. Different polymer mass ratios, namely CS:CM $\beta \mathrm{G} 4: 1$, $2: 1$, and $0.5: 1$, were tested using solutions of both polymers at different concentrations, while keeping the volume ratio constant (1:1). Figure 1 shows that the amount of CS has a major influence in particle size, polydispersity index, and zeta potential. In this case, only nanoparticles with an excess of CS (CS:CM $\beta$ G 4.1 and 2:1) had $\mathrm{PdI}<0.2$, small size, and positive surface charges. These results are in accordance with those reported by other authors, concerning polyelectrolytebased nanoparticles [42-44].

To complete the characterization, we determined the real proportion of both components by elemental analysis (supplementary Fig. 1), observing it was very similar to the theoretical mass ratio. The yield of production was determined to be $85 \%$, which indicates that both polysaccharides were efficiently incorporated into the nanoparticles, with less than $15 \%$ of the total content remaining free in solution.

\section{Association of the model antigen ovalbumin}

Given the particle size, polydispersity index and cationic surface charge obtained for blank nanoparticles, we selected the formulation with a CS:CM $\beta$ G $2: 1$ mass ratio for subsequent OVA association. OVA was included in the aqueous solution of the anionic $\mathrm{CM} \beta \mathrm{G}$, with a $\mathrm{pH}$ of 7.0, where it was negatively charged (isoelectric point of 4.5). Three different theoretical loadings were tested with respect to the total amount of polymers in the formulation, namely 1,3 , and $6.7 \%(\mathrm{w} / \mathrm{w})$. The results showed that, irrespective of the theoretical loading, OVA-loaded NP had a particle size between 160 and $170 \mathrm{~nm}$ and a positive zeta-potential $(+30 \mathrm{mV})$ (supplementary Table 1). For this reason, the nanoparticles with highest OVA loading (6.7\%) were selected for further evaluation.

The morphology of OVA-NP was determined by transmission and scanning electron microscopy (Fig. 2). Electron microscopy images evidence the presence of sphere-shaped structures, corresponding to the common architecture of this type of polysaccharide nanoparticles [12, 45].

OVA-NPs were further characterized to confirm the association of the model protein. For this purpose, the unbound

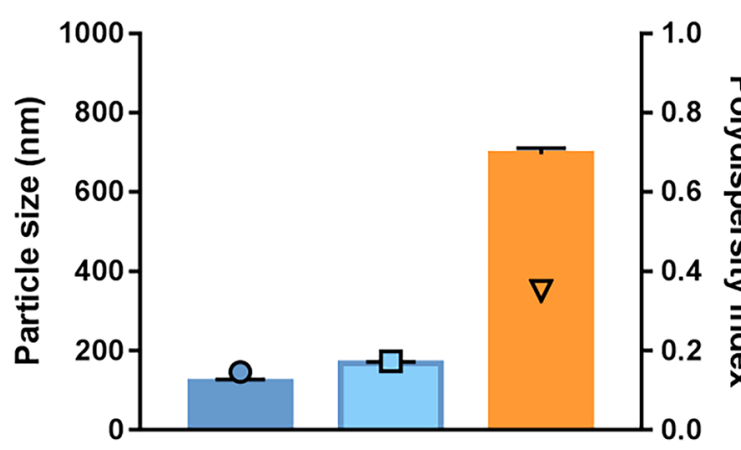

Fig. 1 Particle size distribution and zeta potential of blank CS:CM $\beta \mathrm{G}$ nanoparticles prepared at different polymer mass ratios. Results show mean \pm SD of particle size (bars on left graph), polydispersity index

\section{CS:CMBG 4:1 \\ CS:CM $\beta$ G 2:1 \\ CS:CM $\beta$ G 0.5:1 $\nabla$}

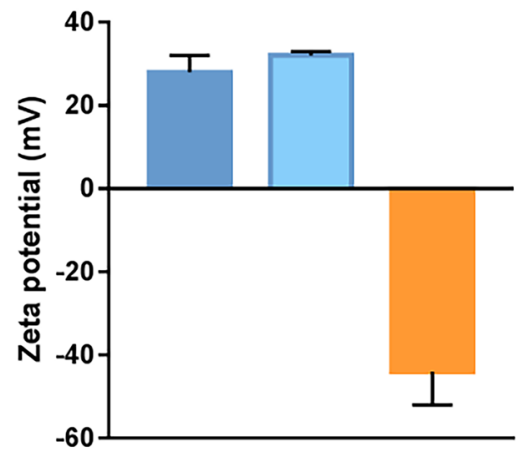

(symbols on left graph), and zeta potential measurements (bars on right graph) of at least three independent replicates. CS chitosan, $\mathrm{CM} \beta \mathrm{G}$ carboxymethyl-beta-glucan 
OVA remaining in the supernatant following centrifugation of the nanoparticles was quantified by Bradford protein assay. With the highest theoretical loading of $6.7 \%$ (w/w), results showed an association efficiency close to $50 \%$ $(46 \pm 19 \%)$. Considering the theoretical OVA loading, its association efficiency and the production yield of the blank nanoparticles, the final loading capacity of the OVA-loaded nanoparticles would be of $3.6 \%(\mathrm{w} / \mathrm{w})$.

Finally, the integrity of the antigen following association to the nanoparticles, was assessed in a Western blot assay, using a specific anti-OVA primary antibody and a secondary fluorescent antibody. As shown in supplementary Fig. 2, the protein band intensity corresponding to ovalbumin associated to $\mathrm{CS}: \mathrm{CM} \beta \mathrm{G}$ nanoparticles was similar to the one corresponding to the control (ovalbumin solution at the same concentration). This leads to the conclusion that antigen integrity was not affected by the association to the NPs, therefore potentially maintaining its immunological properties.

\section{Stability of OVA-loaded CS:CM $\beta$ G nanoparticles and freeze-drying process}

One of the most important challenges in the development of antigen nanocarriers is ensuring their stability in storage conditions. In this regard, we monitored changes in the colloidal properties of OVA-NP when stored at $4{ }^{\circ} \mathrm{C}$ for up to 2 months. Results showed the particle size and polydispersity index of the formulations was maintained in these conditions (supplementary Fig. 3), in accordance with previous works from our group showing that, when formulated in optimal conditions, polymeric antigen nanocarriers can be stable for long periods of time [14, 17, 46, 47].

Developing a dry powder vaccine formulation that could avoid cold chain of storage and resist extreme climate conditions is one of the biggest challenges in the field [48-50]. Hence, our objective was to convert the nanoparticles suspension into a thermostable freeze-dried powder. Based on the experience from our group in the freezedrying of colloidal suspensions $[48,51,52]$, we screened different cryoprotectants commonly used in this process. Figure 3 a shows that all conditions allowed the successful lyophilization of the nanoparticles, which could be resuspended to the initial concentration maintaining their colloidal properties, independently of the type and concentration of cryoprotectant used.

Considering this, we selected sucrose and trehalose for further studies, given their common availability and use in lyophilization. To evaluate the impact of freeze-drying in the overall stability of the nanoparticles, we kept freezedried samples in controlled temperature and humidity conditions, in accordance with the guidelines for accelerated stability testing of drug delivery formulations. The results showed that formulations containing $15 \%$ trehalose remained stable for at least 28 -day storage at $40{ }^{\circ} \mathrm{C}$, as depicted in Fig. $3 b$.

The integrity of the antigen after freeze-drying was also assessed. Western blot images showed similar bands for OVA in the freeze-dried nanoparticles and in solution, at the same concentration, irrespective of the tested conditions (Fig. 3c). The absence of lower molecular weight bands in these gels, as well as the presence of a clear protein band at the same molecular weight of OVA control, at all storage conditions, led us to conclude that the antigen was not visually degraded after freeze-drying and storage at $40{ }^{\circ} \mathrm{C}$ and $75 \%$ humidity for 28 days. Therefore, considering these results, we believe that this prototype holds promising characteristics for antigen delivery. Nevertheless, further studies concerning the biological efficacy of the developed freeze-dried prototype are still required.
Fig. 2 Transmission electron microscopy images of OVAloaded CS:CM $\beta \mathrm{G}$ (2:1 mass ratio, $6.7 \%$ theoretical OVA loading) nanoparticles (scale indicated in the figures)
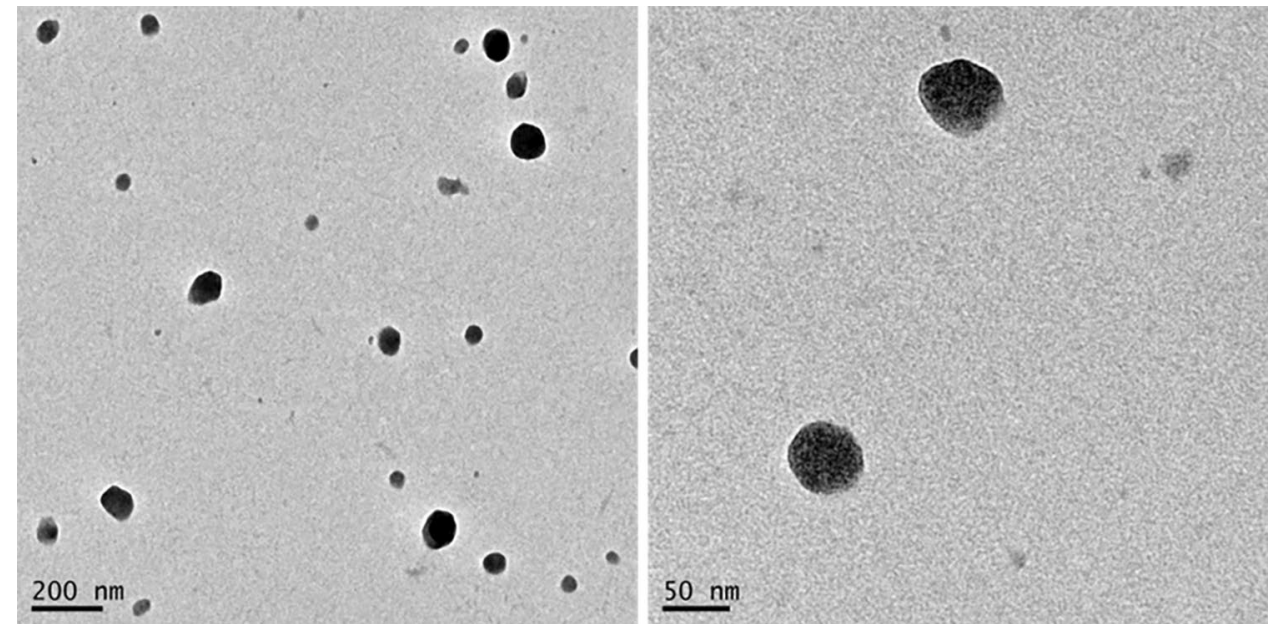
A

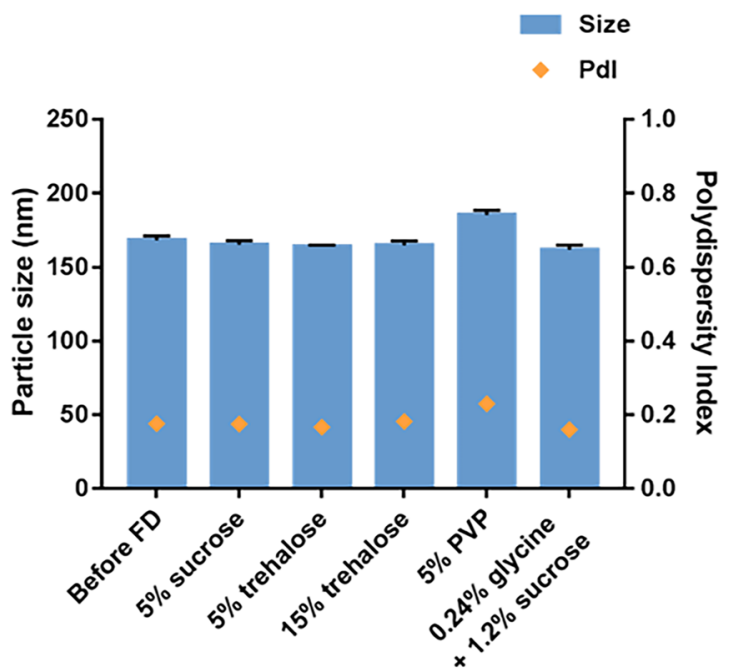

B

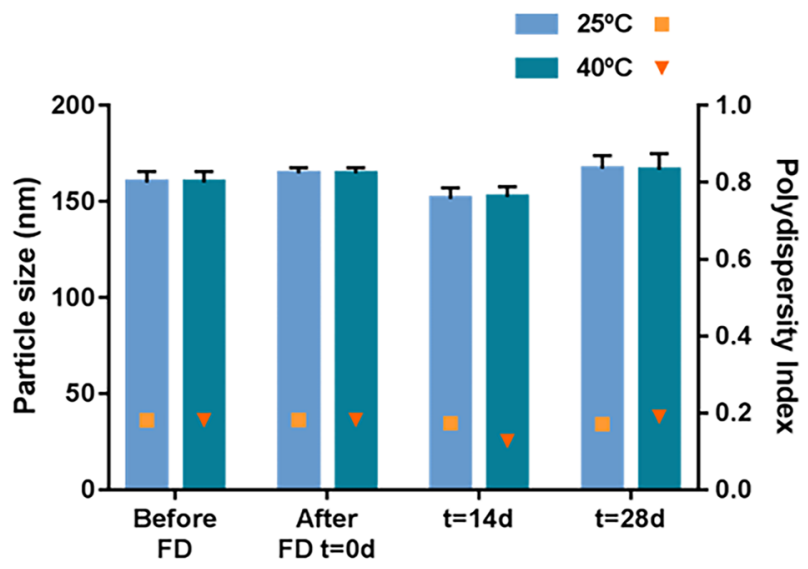

C

50

40

30

20
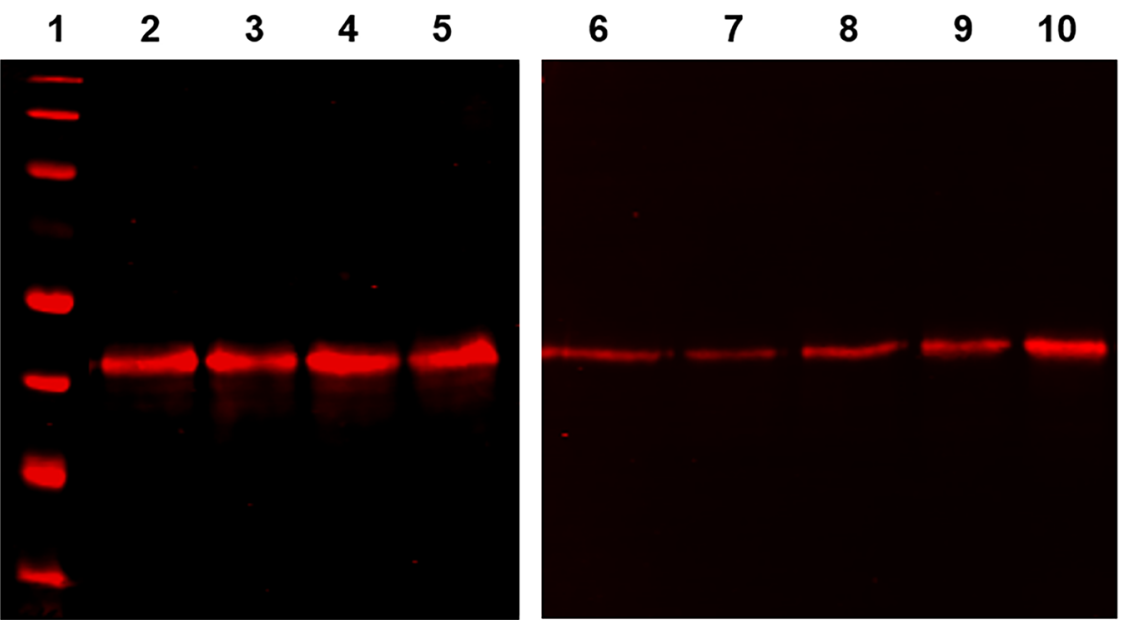

Fig. 3 Freeze-drying (FD) of OVA-loaded CS:CM $\beta$ G nanoparticles. a Screening of freeze-drying conditions. b Stability of formulations freeze-dried with $15 \%$ trehalose $(\mathrm{w} / \mathrm{w})$ (particle size-bars-and polydispersity index-symbols) upon storage at $25^{\circ} \mathrm{C} / 60 \%$ humidity and $40{ }^{\circ} \mathrm{C} / 75 \%$ humidity. c Antigen integrity following freeze-drying with $15 \%$ of trehalose: lane 1 , molecular weight marker $(20-120 \mathrm{kDa})$;

\section{Biodistribution of CS:CM $\beta$ G nanoparticles in the lymphatic system}

Targeting of the lymphatic system by antigen delivery systems is commonly seen as an advantage for immunization, given the abundant presence of APCs in these tissues [53]. In fact, the capture and processing of particulate antigens by $\mathrm{LN}$ resident macrophages and dendritic cells (DCs) usually trigger the development of adequate cellular and humoral immune responses [54]. This targeting approach may be passive, when the physicochemical characteristics of the nanosystems determine their draining to the $\mathrm{LN}$, or active, if the surface of the nanoparticles is decorated with ligands for specific cell recognition [55]. In this work, we hypothesized that both approaches could intervene, as $\mathrm{CM} \beta \mathrm{G}$ can lanes 2 and 6, ovalbumin control $(5 \mu \mathrm{g} / \mathrm{mL})$; lanes 3-5, three replicates of freeze-dried ovalbumin-loaded nanoparticles immediately after resuspension; lanes 7-10, ovalbumin-loaded nanoparticles after freeze-drying and storage at $40{ }^{\circ} \mathrm{C} / 75 \%$ humidity (resuspension done at $7,14,21$, and 28 days after storage, respectively)

be recognized by pattern recognition receptors such as Dectin-1, expressed by different APCs including DCs, and the relatively small size of the particles could also contribute to their facilitated lymphatic drainage.

To validate our hypothesis, we performed a biodistribution assay of CS:CM $\beta \mathrm{G}$ nanoparticles, upon subcutaneous administration to the footpad of mice using imaging protocols, such as two-photon microscopy and flow cytometry. Fluorescent nanoparticles were prepared upon labelling CS with 5-TAMRA, as previously described in our group for other polymers $[52,56]$. In this case, the TAMRA-labelled polymer replaced $25 \%$ of the total amount of CS used in the formulation, to avoid modifying the physicochemical properties of the nanoparticles. 
After subcutaneous administration of the nanoparticles and control polystyrene beads to the footpad of mice, we analyzed the ex vivo images of the draining LN. Control beads were used for normalization of the results and to minimize the variability associated to the injection process. We compared the behavior of blank nanoparticles and OVA-NP to determine their biodistribution, assessing if the antigen itself could have an effect in that process. Popliteal LN were collected $12 \mathrm{~h}$ post-administration. It is worth mentioning that at this time point phagocytes are the first cells to encounter the antigen transported by the lymph, so, in line with previous results obtained in our group [57], we expected the main interaction of the particles to be with APCs and not with follicular B cells.
The results in Fig. 4 show that both blank and OVAloaded nanoparticles reached the $\mathrm{LN}$, and were efficiently taken-up by dendritic cells. Figure 4 a shows a representative image of one LN, in which the accumulation of the OVANP (in red), is visible in the medullary and interfollicular regions. Some degree of co-localization with the control polystyrene beads is visible in yellow regions (overlapping of green and red labelling). The quantification of fluorescence intensity, as measured by flow cytometry, confirmed there was no influence of the antigen in the lymphatic accumulation of the nanoparticles (Fig. 4b). As previously mentioned, the size and surface charge of the nanoparticles [29, 53, 57], as well as the ability of $\mathrm{CM} \beta \mathrm{G}$ to interact with complement

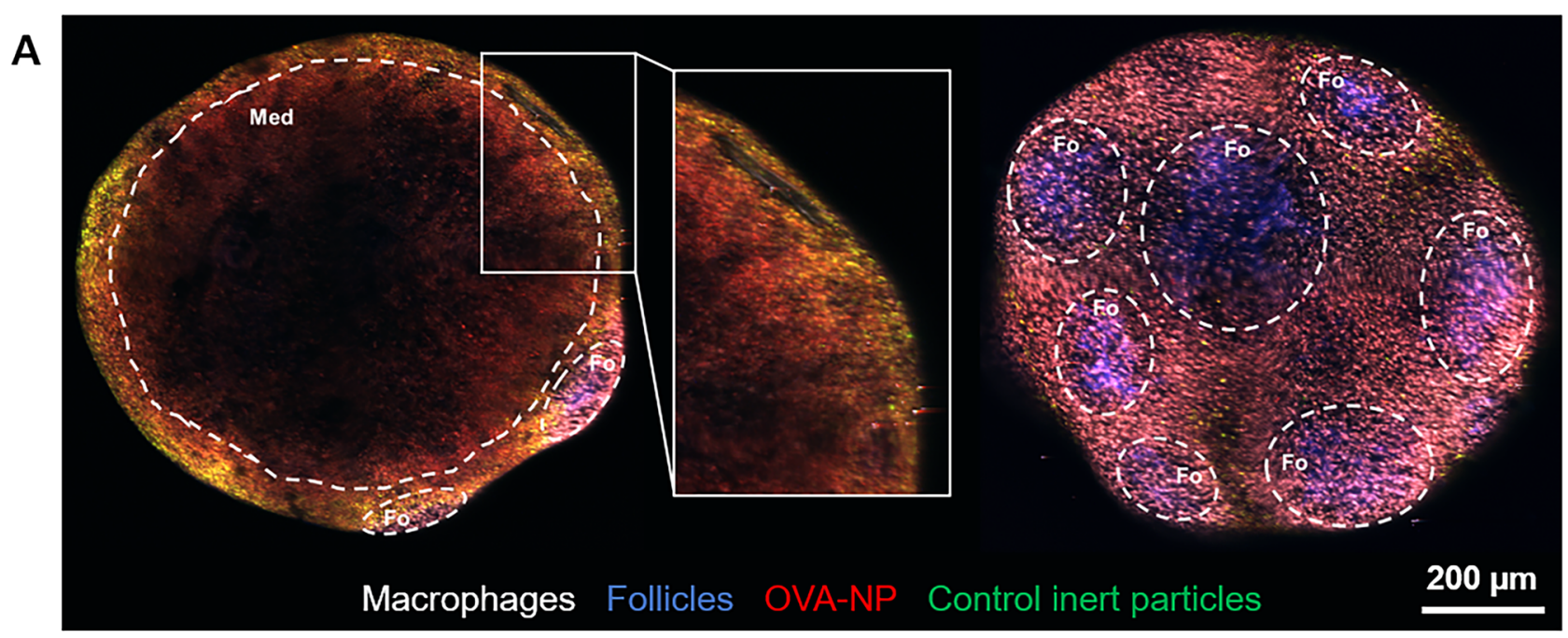

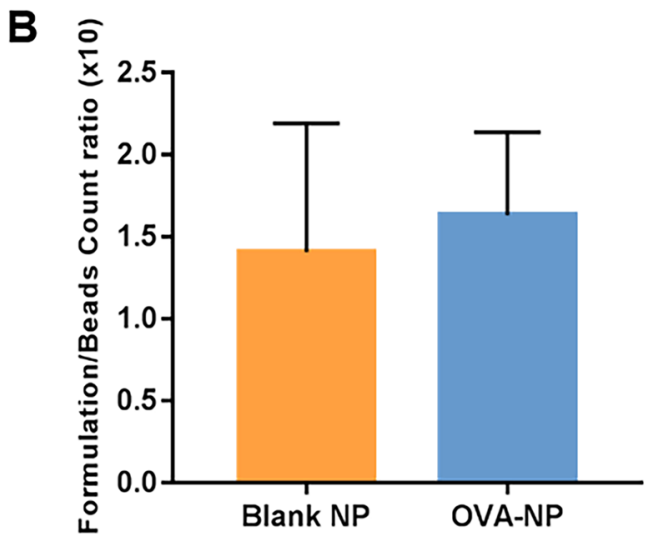

Fig. 4 Distribution of CS:CM $\beta \mathrm{G}$ nanoparticles (blank or loaded with ovalbumin, OVA-NP) in popliteal LN, after subcutaneous injection. Ex vivo, 2-photon microscopy images a show the accumulation of OVA-loaded nanoparticles in the medullary (left) and follicular (right) areas of popliteal LN. A detail of the medullary region, with a follicle in the back, is seen in the middle image. Macrophages are shown in white (CD169-AF 647), follicles in blue (CD21/35-PB), nanoparticles in red (TAMRA) and control polystyrene beads in
C

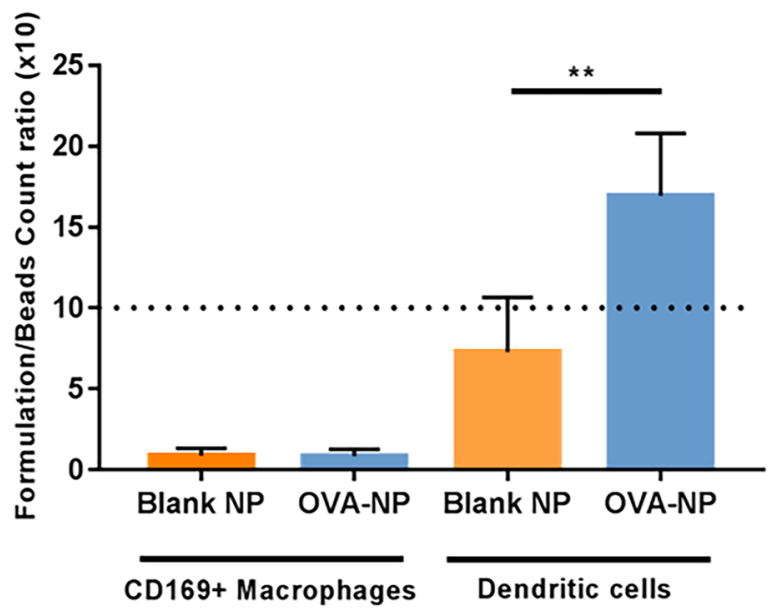

green (Firefli ${ }^{\mathrm{TM}}$ Fluorescent Green). Images of the separate channels for each of the images (medullary and follicular views) can be seen in Fig. S4 (supplementary materials). Fluorescence intensity was quantified by flow cytometry, in the total number of cells of the LN b and in two cell populations, macrophages and dendritic cells c. Results were normalized using the signal obtained for fluorescent polystyrene beads co-administered with the nanosystems (dot line represents equal accumulation of nanocapsules and beads). $* * p<0.01$ 
receptor 3 (CR3) and Dectin-1 receptor present in APCs [20-22], could explain this positive biodistribution profile.

To further understand the specific biodistribution of OVA-NP, we quantified the fluorescence intensity in populations of macrophages and DCs from the popliteal LN. The results, shown in Fig. 4c, suggest a preferential interaction of both types of nanoparticles with DCs. This is in accordance with our recent study with polymeric nanocapsules subcutaneously administered to mice, in which we observed a similar trend of preferential interaction with DCs [57]. This preferential interaction was particularly striking in the case of OVA-NP, which may be related to the specialized ability

A
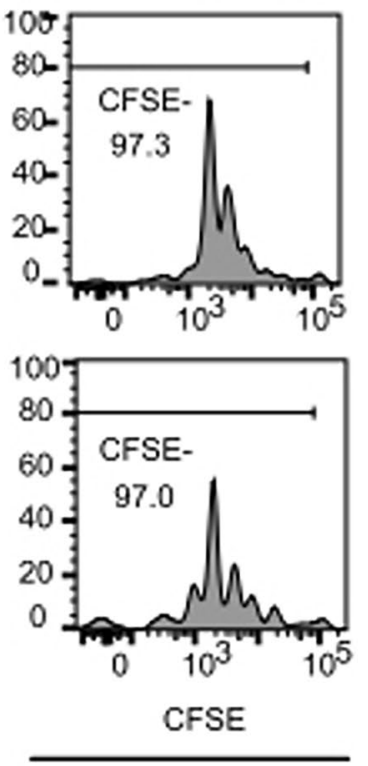

LN1
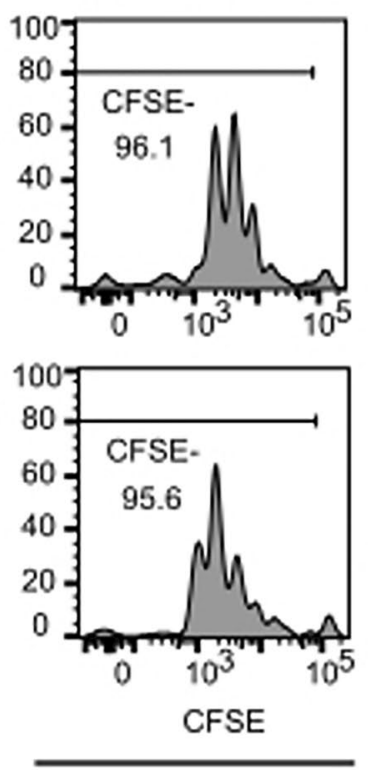

LN2

B

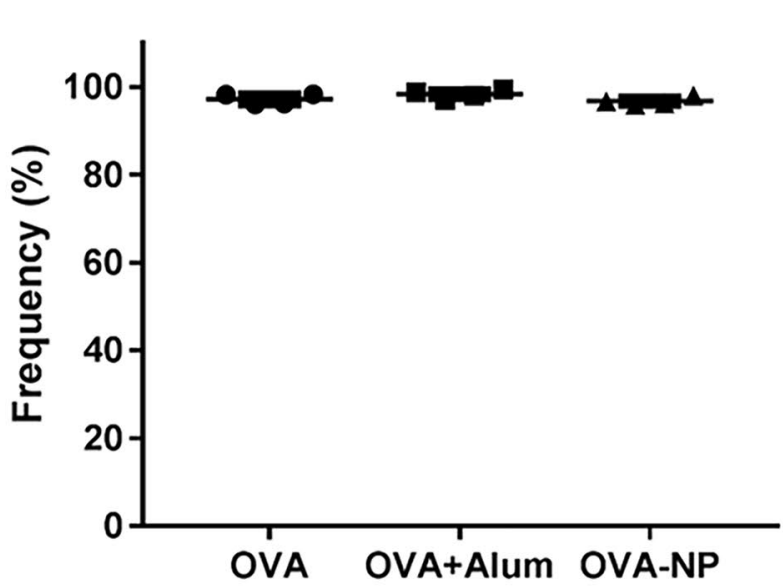

Fig. 5 Proliferation of OVA-specific $\mathrm{CD}^{+} \mathrm{T}$ cells collected from mice popliteal $\mathrm{LN}$ at day 2 after subcutaneous administration of ovalbumin in solution (OVA), alum-adsorbed OVA (OVA + Alum), or OVA-loaded CS:CM $\beta$ G nanoparticles (OVA-NP). a Example proliferation histograms of transferred $\mathrm{CD}^{+} \mathrm{T}$ cells in the popliteal $\mathrm{LN}$ of of DCs to recognize different types of antigens. Supporting this, DCs have previously shown an efficient uptake of OVAconjugated yeast glucan microparticles, upon subcutaneous administration to mice. In this study, this uptake has then translated into an efficient antigen presentation and immune response in an anticancer therapeutic approach [58]. Similarly, nanoparticles prepared with an aminated beta glucan, CpG oligodeoxynucleotide, and OVA were described by Jin et al. as capable of activating DCs and inducing cytokine secretion in vitro to a higher degree than free OVA [31]. Potentially, the combination of $\mathrm{CM} \beta \mathrm{G}$, which is recognized by DCs through Dectin-1, and OVA, which is recognized

\section{OVA-NP}

\section{OVA+Alum}

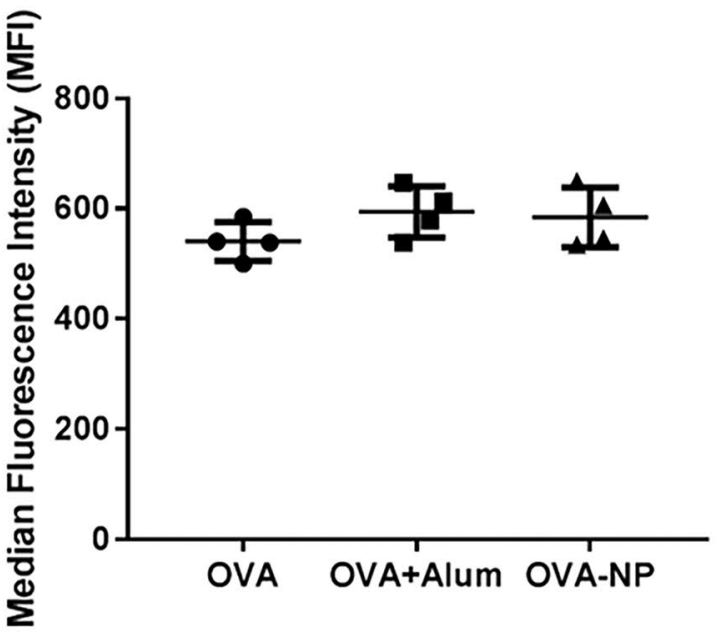

mice immunized with the developed nanoparticles or with the positive control (alum-adsorbed OVA). b Frequency (left) and median fluorescence intensity (right) plots for CFSE- populations in each treated group. No significant differences were observed between any of the groups studied 
by DCs as an antigen, may be responsible for the observed increased interaction between OVA-NP and these cells.

Overall, our results show an accumulation of the nanoparticles in the $\mathrm{LN}$ and an efficient uptake of these carriers by dendritic cells. Therefore, we considered this prototype as interesting for further studies concerning its adjuvant potential.

\section{In vivo immune response}

The process of generation of an adaptive response involves the recognition of antigens displayed by APCs (particularly DCs) by T cells [59]. Adjuvants have an essential role in this process, and the stimulation of $\mathrm{T}$ cell proliferation following immunization can therefore be an indication of the adjuvant potential. Considering this, we evaluated the behavior of $\mathrm{CD} 4^{+} \mathrm{T}$ cells following subcutaneous immunization of mice with the developed formulations. These cells are particularly relevant in recruiting phagocytes and in helping antibody production by B lymphocytes, being critical in the "cellmediated" arm of the immune response.

One day before immunization, OVA-specific $\mathrm{CD}^{+}{ }^{+} \mathrm{T}$ cells labelled with CFSE were injected into C57/B6 mice. CFSE is an intracellular fluorescent dye, and therefore its levels within each cell decrease with each cellular division. Consequently, a decrease in median fluorescence intensity (MFI) and/or in the frequency of $\mathrm{CFSE}^{-}$cells is commonly used to indicate $\mathrm{T}$ cell proliferation. The mice were then subcutaneously immunized with OVA-NP or the controls (i.e., a negative control, OVA in solution, and a positive control, alum-adsorbed OVA). At day 2 post-immunization, the draining $\mathrm{LN}$ were collected to evaluate the degree of proliferation of the transferred cells, which is related to an adequate antigen presentation by DCs.

As shown in Fig. 5a, the level of proliferation of $\mathrm{CD} 4^{+}$ $\mathrm{T}$ cells exposed to free OVA, OVA-NP and alum-adsorbed OVA was similar, with no significant differences observed. This was also corroborated by the median CFSE fluorescence intensities values observed for these formulations (Fig. 5b). These results indicate that CS:CM $\beta$ G nanoparticles were able to deliver the model antigen to DCs, the results of which was the stimulation of $\mathrm{T}$ cells proliferation at least to the same level as the standard adjuvant alum. The absence of significant differences between all groups suggest the ability of the antigen to be recognized by APCs and initiate the immune response is not affected by its association to the NPs or alum. In previous work, we have shown the ability of polysaccharide nanoparticles, prepared with CS and dextran, to activate both $\mathrm{CD}^{+}$and $\mathrm{CD} 8^{+} \mathrm{T}$ cells in mice, following intramuscular immunization with an HIV peptide antigen [15]. Similarly, Yang et al. showed enhanced T cell proliferation in vivo, following two subcutaneous immunizations of mice with ovalbumin-loaded glucan particles [60].

To further assess the adjuvant potential of these new nanocarriers, we evaluated the antibody and antibodysecreting cell (ASC) levels generated in mice following
Fig. 6 Antibody (IgG and IgG2a) a and antibody-secreting cell (ASC) b levels elicited in mice following subcutaneous immunization with ovalbumin in solution (OVA), alumadsorbed OVA (OVA + Alum), or OVA-loaded CS:CM $\beta$ G nanoparticles (OVA-NP). The differences between OVA + Alum and OVA-NP groups were not significant. $* p<0.05$
A
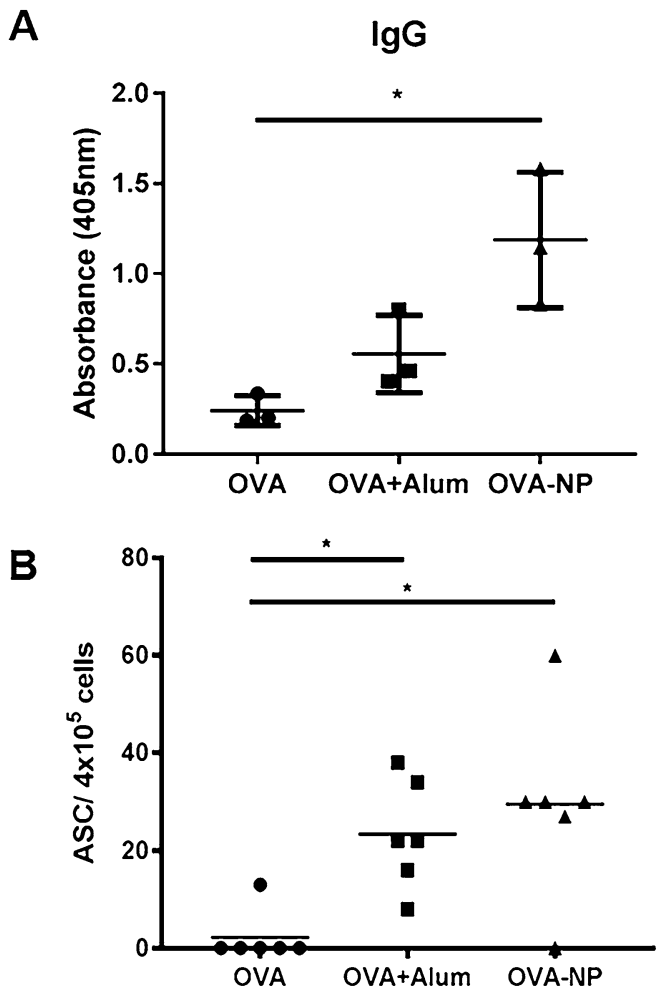

$\lg G 2 a$

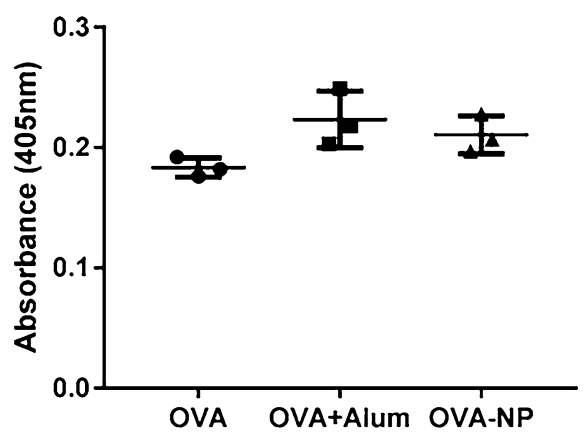


immunization with our prototype. As shown in Fig. 6a, the total IgG levels induced by antigen-loaded CS:CM $\beta \mathrm{G}$ nanoparticles were similar to those achieved with the alumadsorbed antigen, though only the nanoparticles induced a significantly higher response in comparison with the antigen in solution. Interestingly, the previously discussed $\mathrm{T}$ cell proliferation results (Fig. 5) did not show significant differences between the three groups, a result that may suggest that antigen presentation of OVA when associated to NPs is mediated by a different mechanism, not associated to $\mathrm{CD} 4^{+}$ T cells.

When quantifying the levels of the $\operatorname{IgG}$ subtype $\operatorname{IgG} 2 \mathrm{a}$, conventionally associated with a cellular response, we did not observe any differences between the immunization strategies tested. Protein antigens such as ovalbumin are known to mainly induce humoral responses with high production of IgG1 [61]; however, higher levels of IgG2a could also be related with a recognition of CM $\beta G$ by the immune system, since this antibody is commonly responsible for the recognition of bacterial capsular polysaccharides [62]. This may be related to the use of a synthetically modified $\beta$-glucan instead of the original yeast glucan particles previously described in the literature [24, $26,27,35]$. Nevertheless, it is encouraging to observe in our results an improved immune response against OVA-NP in comparison with controls, despite the probable absence of recognition of $\mathrm{CM} \beta \mathrm{G}$ itself as an antigen. In agreement with these antibody results, we observed a significantly higher response in terms of ASC levels in the animals immunized with OVA-NP, in comparison with the soluble antigen (Fig. 6b). These results suggest an early involvement of B cells in the antigen-specific immune response generated following immunization.

The promising in vivo results obtained with the developed nanoparticles open the possibility of their application to the delivery of other protein antigens relevant to various infectious diseases, though further studies with larger cohorts of animals and a more detailed overview of the immune response generated would be necessary in future development.

\section{Conclusions}

Here, we describe a new type of nanoparticles combining two polysaccharides with immunomodulatory properties, $\mathrm{CS}$ and $\mathrm{CM} \beta \mathrm{G}$, and loaded with a model antigen, OVA. In preliminary in vivo studies, the nanoparticles showed an efficient accumulation in draining lymph nodes upon subcutaneous administration to mice, as well as adequate interaction with APCs, leading to T cell activation and proliferation. This approach also elicited antibody levels in mice similar to those achieved with alum-adsorbed OVA, 10 days after a single subcutaneous immunization. Moreover, these nanoparticles could be transformed into a freeze-dried thermostable formulation, which is particularly relevant considering the critical limitations imposed to vaccine production and distribution.

Supplementary Information The online version contains supplementary material available at https://doi.org/10.1007/s13346-021-00968-9.

Author contribution (As by CRediT taxonomy) Conceptualization, A.S.C., J.C-C., S.F.G., M.J.A.; data curation, A.S.C., Y.F.; investigation, A.S.C., Y.F.; methodology, A.S.C., Y.F.; formal analysis, A.S.C., Y.F.; visualization, A.S.C.; writing-original draft, A.S.C.; writing-review and editing, A.S.C., Y.F., J.C-C., M.F., S.F.G., M.J.A.; resources, S.F.G., M.J.A.; supervision, J.C-C., M.F., S.F.G., M.J.A.; project administration, M.J.A.

Funding This study is financially supported by the Ministry of Economy and Competitiveness-MINECO (RETOS MINECO: Aplicación de la nanotecnología al desarrollo de vacunas para autoinmunidad (NANOT-AID), Ref. BIO2014-53091-C3-2-R), the Carlos III Health Institute-ISCIII (CP12/03150), and the Xunta de Galicia (Competitive Reference Groups, Consellería de Educación e Ordenación Universitaria, Ref: ED431C 2017/09). The first author was supported by a predoctoral grant from the FPI program of the MINECO (BES-2012-057183).

\section{Declarations}

Declaration on animal studies All experiments complied with the Swiss Federal Veterinary Office guidelines and the veterinarian local authorities approved animal protocols.

\section{References}

1. Gori A, Longhi R, Peri C, Colombo G. Peptides for immunological purposes: design, strategies and applications. Amino Acids . 2013;45:257-68. https://doi.org/10.1007/s00726-013-1526-9

2. Bobbala $S$, Hook S. Is There an Optimal Formulation and Delivery Strategy for Subunit Vaccines? Pharm Res. 2016;33:2078-97. https://doi.org/10.1007/s11095-016-1979-0

3. Shin MD, Shukla S, Chung YH, Beiss V, Chan SK, Ortega-Rivera OA, Wirth DM, Chen A, Sack M, Pokorski JK, Steinmetz NF. COVID-19 vaccine development and a potential nanomaterial path forward. Nat nanotechnology. 2020;15(8):646-55. https:// doi.org/10.1038/s41565-020-0737-y

4. Shi S, Zhu H, Xia X, Liang Z, Ma X, Sun B. Vaccine adjuvants: Understanding the structure and mechanism of adjuvanticity. Vaccine. 2019;37(24):3167-78. https://doi.org/10.1016/j. vaccine.2019.04.055

5. O'Hagan DT, Friedland LR, Hanon E, Didierlaurent AM. Towards an evidence based approach for the development of adjuvanted vaccines. Curr Opin Immunol. Elsevier Ltd; 2017;47:93-102. https://doi.org/10.1016/j.coi.2017.07.0102017

6. Simón-Vázquez R, Peleteiro $\mathrm{M}$, González-Fernández Á. Polymeric nanostructure vaccines: applications and challenges. Expert Opin Drug Deliv. Taylor \& Francis; 2020;17:1007-23. https://doi.org/10.1080/17425247.2020.1776259 
7. Cordeiro AS, Alonso MJ. Recent advances in vaccine delivery. Pharm Pat Anal. 2016;5:49-73. http://www.future-science.com/ doi/10.4155/ppa.15.38

8. Irvine DJ, Swartz MA, Szeto GL. Engineering synthetic vaccines using cues from natural immunity. Nat Mater. 2013;12:97890. http://www. pubmedcentral.nih.gov/articlerender. fcgi? artid $=3928825 \&$ tool $=$ pmcentrez\&rendertype $=$ abstract

9. Kreuter J, Speiser PP. New adjuvants on a polymethylmethacrylate base. Infect Immun. 1976;13:204-10. http://iai.asm.org/content/13/1/204.short

10. Cordeiro AS, Alonso MJ, de la Fuente M. Nanoengineering of vaccines using natural polysaccharides. Biotechnol Adv. Elsevier Inc.;2015;33:1279-93. https://doi.org/10.1016/j.biotechadv.2015. 05.010

11. Mahla RS, Reddy MC, Prasad DVR, Kumar H. Sweeten PAMPs: Role of sugar complexed PAMPs in innate immunity and vaccine biology. Front Immunol. 2013;4:248.

12. Prego C, Paolicelli P, Díaz B, Vicente S, Sánchez A, GonzálezFernández Á, et al. Chitosan-based nanoparticles for improving immunization against hepatitis B infection. Vaccine. 2010;28:2607-14. http://www.sciencedirect.com/science/article/pii/S0264410X10000423

13. Vicente S, Peleteiro M, Díaz-Freitas B, Sánchez A, GonzálezFernández Á, Alonso MJ, et al. Co-delivery of viral proteins and a tlr7 agonist from polysaccharide nanocapsules: A needlefree vaccination strategy. J Control Release. Elsevier B.V.; 2013;172:773-81. http://www.sciencedirect.com/science/ article/pii/S0168365913008006

14. Correia-Pinto JF, Csaba N, Schiller JT, Alonso MJ. Chitosanpoly (I:C)-PADRE based nanoparticles as delivery vehicles for synthetic peptide vaccines. Vaccines. 2015;3:730-50. http://www. mdpi.com/2076-393X/3/3/730/

15. Dacoba TG, Omange RW, Li H, Crecente-Campo J, Luo M, Alonso MJ. Polysaccharide nanoparticles can efficiently modulate the immune response against an HIV peptide antigen. ACS Nano. 2019;13:4947-59. https://pubs.acs.org/doi/10.1021/ acsnano.8b07662

16. Vila A, Sánchez A, Janes KA, Behrens I, Kissel T, Vila-Jato JL, et al. Low molecular weight chitosan nanoparticles as new carriers for nasal vaccine delivery in mice. Eur J Pharm Biopharm. 2004;57:123-31. http://linkinghub.elsevier.com/retrieve/ pii/S0939641103001620

17. Dacoba TG, Ruiz-Gatón L, Benito A, Klein M, Dupin D, Luo $\mathrm{M}$, et al. Technological challenges in the preclinical development of an HIV nanovaccine candidate. Drug Deliv Transl Res. 2020;10:621-34. http://link.springer.com/10.1007/ s13346-020-00721-8

18. Novak M, Vetvicka V. Beta-glucans, history, and the present: immunomodulatory aspects and mechanisms of action. $\mathrm{J}$ Immunotoxicol. 2008;5:47-57.

19. Demento SL, Siefert AL, Bandyopadhyay A, Sharp FA, Fahmy TM. Pathogen-associated molecular patterns on biomaterials: a paradigm for engineering new vaccines. Trends Biotechnol. 2011;29:294-306. http://www.sciencedirect.com/science/article/ pii/S0167779911000369

20. Jin Y, Li P, Wang F. $\beta$-glucans as potential immunoadjuvants: a review on the adjuvanticity, structure-activity relationship and receptor recognition properties. Vaccine. Elsevier Ltd; 2018;36:5235-44. https://doi.org/10.1016/j.vaccine.2018.07.038

21 . Goodridge HS, Wolf AJ, Underhill DM. $\beta$-glucan recognition by the innate immune system. Immunol Rev. Blackwell Publishing Ltd; 2009;230:38-50. https://doi.org/10.1111/j.1600-065X.2009. 00793.x

22. Huang H, Ostroff GR, Lee CK, Agarwal S, Ram S, Rice PA, et al. Relative contributions of Dectin-1 and complement to immune responses to particulate beta-glucans. J Immunol. 2012;189:3127. http://www.jimmunol.org/lookup/doi/10.4049/jimmunol.1200603
23. De Smet R, Demoor T, Verschuere S, Dullaers M, Ostroff GR, Leclercq $\mathrm{G}$, et al. $\beta$-Glucan microparticles are good candidates for mucosal antigen delivery in oral vaccination. J Control Release. Elsevier B.V.; 2013;172:671-8. https://doi.org/10.1016/j.jconrel. 2013.09.007

24. Baert K, De Geest BG, De Rycke R, Antunes AB da F, De Greve $\mathrm{H}$, Cox E, et al. $\beta$-glucan microparticles targeted to epithelial APN as oral antigen delivery system. J Control Release. Elsevier B.V.; 2015;220:149-59. https://doi.org/10.1016/j.jconrel.2015.10.025

25. Specht CA, Lee CK, Huang H, Hester MM, Liu J, Luckie BA, et al. Vaccination with recombinant cryptococcus proteins in glucan particles protects mice against cryptococcosis in a manner dependent upon mouse strain and cryptococcal species. MBio. 2017;8:e01872-17. http://mbio.asm.org/lookup/doi/10.1128/ mBio.01872-17

26. Whelan AO, Flick-Smith HC, Homan J, Shen ZT, Carpenter Z, Khoshkenar P, et al. Protection induced by a Francisella tularensis subunit vaccine delivered by glucan particles. Bakshi CS, editor. PLoS One. 2018;13:e0200213. https://dx.plos.org/10.1371/journal. pone.0200213

27. Baert K, De Geest BG, De Greve H, Cox E, Devriendt B. Duality of $\beta$-glucan microparticles: antigen carrier and immunostimulants. Int $\mathrm{J}$ Nanomedicine. 2016;11:2463. https://www.dovepress.com/duality-ofbeta-glucan-microparticles-antigen-carrier-and-immunostimul-peerreviewed-article-IJN

28. Shah RR, O'Hagan DT, Amiji MM, Brito LA. The impact of size on particulate vaccine adjuvants. Nanomedicine. 2014;9:2671-81. https://www.futuremedicine.com/doi/10.2217/nnm.14.193

29. Benne N, van Duijn J, Kuiper J, Jiskoot W, Slütter B. Orchestrating immune responses: How size, shape and rigidity affect the immunogenicity of particulate vaccines. J Control Release. Elsevier B.V.; 2016;234:124-34. http://linkinghub.elsevier.com/ retrieve/pii/S0168365916303133

30. Liang H, Xiao X, Zhang X, Hu Q, Yang Y, Cen S, et al. Selfassembled nanovehicle-mediated co-encapsulation of inactivated EV71 virus and $\mathrm{CpG}$ oligonucleotides elicits potent anti-EV71 humoral and cellular immune protective responses. Biochem Biophys Res Commun. Elsevier Ltd; 2019;511:253-9. https:// doi.org/10.1016/j.bbrc.2019.02.014

31. Jin JW, Tang SQ, Rong MZ, Zhang MQ. Synergistic effect of dual targeting vaccine adjuvant with aminated $\beta$-glucan and CpGoligodeoxynucleotides for both humoral and cellular immune responses. Acta Biomater. Acta Materialia Inc.; 2018;78:211-23. https://doi.org/10.1016/j.actbio.2018.08.002

32. Ernst $\mathrm{O}$, Zor T. Linearization of the bradford protein assay. $\mathrm{J}$ Vis Exp JoVE. JoVE; 2010;e1918. http://www.jove.com/video/1918

33. U.S. Food and Drug Administration. Guidance for industry Q1A(R2) stability testing of new drug substances and products. ICH Guidel. 2003 [cited 2021 Mar 15]. https://www.fda.gov/ media/71707/download

34. Soares E, Jesus S, Borges OM. Chitosan: $\beta$-glucan particles as a new adjuvant for the hepatitis B antigen. Eur J Pharm Biopharm. Elsevier; 2018;131:33-43. https://linkinghub.elsevier.com/ retrieve/pii/S0939641118302686

35. Soares E, Groothuismink ZM, Boonstra A, Borges OM. Glucan particles are a powerful adjuvant for the $\mathrm{HBsAg}$, favoring antiviral immunity. Mol Pharm. 2019;16:1971-81. https://pubs.acs.org/doi/ 10.1021/acs.molpharmaceut.8b01322

36. Soares E, Cordeiro R, Faneca H, Borges OM. Polymeric nanoengineered HBsAg DNA vaccine designed in combination with $\beta$-glucan. Int J Biol Macromol. Elsevier B.V.; 2019;122:9309. https://doi.org/10.1016/j.ijbiomac.2018.11.024

37. Cordeiro AS, Crecente-Campo J, López-Bouzo B, González SF, de la Fuente M, Alonso MJ. Engineering polymeric nanocapsules for an efficient drainage and biodistribution in the lymphatic 
system. J Drug Target. Taylor \& Francis; 2019;27:646-58. https:// www.tandfonline.com/doi/full/10.1080/1061186X.2018.1561886

38. Calvo P, Remuñán-López C, Vila-Jato JL, Alonso MJ. Chitosan and Chitosan/Ethylene Oxide-Propylene Oxide Block Copolymer Nanoparticles as Novel Carriers for Proteins and Vaccines. Pharm Res. Springer Netherlands; 1997;14:1431-6. http://link.springer. com.docelec.univ-lyon1.fr/article/10.1023/A:1012128907225\% 5Cn\%3CGo to ISI\%3E://A1997YD50200019

39. Drogoz A, Munier S, Verrier B, David L, Domard A, Delair T. Towards biocompatible vaccine delivery systems: interactions of colloidal PECs based on polysaccharides with HIV-1 p24 antigen. Biomacromolecules. 2008;9:583-91. http://www.ncbi.nlm.nih. gov/pubmed/18208314

40. Sharma S, Mukkur TK, Benson HA, Chen Y. Enhanced immune response against pertussis toxoid by IgA-loaded chitosan-dextran sulfate nanoparticles. J Pharm Sci. 2012;101:233-44. https://doi. org/10.1002/jps.22763

41. Pawar D, Jaganathan K. Mucoadhesive glycol chitosan nanoparticles for intranasal delivery of hepatitis B vaccine: enhancement of mucosal and systemic immune response. Drug Deliv. 2016;23:185-94. https://www.tandfonline.com/doi/full/ 10.3109/10717544.2014.908427

42. Drogoz A, David L, Rochas C, Domard A, Delair T. Polyelectrolyte complexes from polysaccharides: formation and stoichiometry monitoring. Langmuir. 2007;23:10950-8.

43. de la Fuente M, Seijo B, Alonso MJ. Design of novel polysaccharidic nanostructures for gene delivery. Nanotechnology . 2008;19:075105. http://www.ncbi.nlm.nih.gov/pubmed/ 21817630

44. Alonso-Sande M, Cuña M, Remuñán-López C, Teijeiro-Osorio D, Alonso-Lebrero JL, Alonso MJ. Formation of new glucomannanchitosan nanoparticles and study of their ability to associate and deliver proteins. Macromolecules. American Chemical Society; 2006;39:4152-8. http://pubs.acs.org/doi/abs/10.1021/ma060230j

45. de la Fuente M, Seijo B, Alonso MJ. Novel hyaluronan-based nanocarriers for transmucosal delivery of macromolecules. Macromol Biosci. 2008;8:441-50. http://www.ncbi.nlm.nih.gov/ pubmed/18236434

46. González-Aramundiz JV, Olmedo MP, González-Fernández Á, Alonso Fernández MJ, Csaba NS. Protamine-based nanoparticles as new antigen delivery systems. Eur J Pharm Biopharm. 2015;97:51-9. http://www.ncbi.nlm.nih.gov/pubmed/ 26455338

47. Crecente-Campo J, Lorenzo-Abalde S, Mora A, Marzoa J, Csaba $\mathrm{N}$, Blanco J, et al. Bilayer polymeric nanocapsules: a formulation approach for a thermostable and adjuvanted E. coli antigen vaccine. J Control Release. Elsevier; 2018;286:20-32. https://doi. org/10.1016/j.jconrel.2018.07.018

48. Vicente S, Díaz-Freitas B, Peleteiro M, Sanchez A, Pascual DW, González-Fernández Á, et al. A polymer/oil based nanovaccine as a single-dose immunization approach. PLoS One. Public Library of Science; 2013;8:e62500. http://dx.doi.org/10.1371/journal. pone. 0062500

49. Tonnis WF, Amorij J-P, Vreeman M, Frijlink H, Kersten GF, Hinrichs WL. Improved storage stability and immunogenicity of hepatitis B vaccine after spray-freeze drying in presence of sugars. Eur J Pharm Sci. Elsevier B.V.; 2014;55:36-45. http://dx.doi.org/ 10.1016/j.ejps.2014.01.005
50. Mody KT, Mahony D, Cavallaro AS, Stahr F, Qiao SZ, Mahony TJ, et al. Freeze-drying of ovalbumin loaded mesoporous silica nanoparticle vaccine formulation increases antigen stability under ambient conditions. Int J Pharm. Elsevier B.V.; 2014;465:325-32. http://dx.doi.org/10.1016/j.ijpharm.2014.01.037

51. Lozano MV, Esteban H, Brea J, Loza MI, Torres D, Alonso MJ. Intracellular delivery of docetaxel using freeze-dried polysaccharide nanocapsules. J Microencapsul. 2013;30:181-8. http://www.ncbi.nlm.nih.gov/pubmed/23088320

52. González-Aramundiz JV, Presas E, Dalmau-Mena I, MartínezPulgarín S, Alonso C, Escribano JM, et al. Rational design of protamine nanocapsules as antigen delivery carriers. J Control Release . Elsevier B.V.; 2017;245:62-9. http://dx.doi.org/10. 1016/j.jconrel.2016.11.012

53. Thomas SN, Schudel A. Overcoming transport barriers for interstitial-, lymphatic-, and lymph node-targeted drug delivery. Curr Opin Chem Eng. Elsevier Ltd; 2015;7:65-74. http://dx.doi. org/10.1016/j.coche.2014.11.003

54. Gause KT, Wheatley AK, Cui J, Yan Y, Kent SJ, Caruso F. Immunological principles guiding the rational design of particles for vaccine delivery. ACS Nano. 2017;11:54-68. http://pubs.acs. org/doi/abs/10.1021/acsnano.6b07343

55. Gutjahr A, Phelip C, Coolen A-L, Monge C, Boisgard A-S, Paul $\mathrm{S}$, et al. Biodegradable polymeric nanoparticles-based vaccine adjuvants for lymph nodes targeting. Vaccines. 2016;4:34. http:// www.mdpi.com/2076-393X/4/4/34

56. Reimóndez-Troitiño $\mathrm{S}$, Alcalde I, Csaba N, Íñigo-Portugués A, de la Fuente M, Bech F, et al. Polymeric nanocapsules: a potential new therapy for corneal wound healing. Drug Deliv Transl Res. 2016;6:708-21. http://link.springer.com/10.1007/ s13346-016-0312-0

57. Crecente-Campo J, Virgilio T, Morone D, Calviño-Sampedro C, Fernández-Mariño I, Olivera A, et al. Design of polymeric nanocapsules to improve their lympho-targeting capacity. Nanomedicine. 2019;14:3013-33. https://www.futuremedicine. com/doi/10.2217/nnm-2019-0206

58. Pan Y, Li X, Kang T, Meng H, Chen Z, Yang L, et al. Efficient delivery of antigen to DCs using yeast-derived microparticles. Sci Rep . Nature Publishing Group; 2015;5:10687. http://www. pubmedcentral.nih.gov/articlerender.fcgi? $\operatorname{artid}=4650639 \&$ tool $=$ pmcentrez\&rendertype $=$ abstract

59. Abbas AK, Lichtman AH, Pillai S. Cellular and Molecular Immunology. 8th ed. Abbas AK, Lichtman AH, Pillai S, editors. Philadelphia (PA): Elsevier; 2015.

60. Yang Z, Xu M, Jia Z, Zhang Y, Wang L, Zhang H, et al. A novel antigen delivery system induces strong humoral and CTL immune responses. Biomaterials. Elsevier Ltd; 2017;134:51-63. https://doi. org/10.1016/j.biomaterials.2017.04.035

61. Vidarsson G, Dekkers G, Rispens T. IgG subclasses and allotypes: From structure to effector functions. Front Immunol. 2014;5:1-17.

62. Siber GR, Schur PH, Aisenberg AC, Weitzman SA, Schiffman G. Correlation between serum IgG-2 concentrations and the antibody response to bacterial polysaccharide antigens. N Engl J Med. 1980;303:178-82.

Publisher's Note Springer Nature remains neutral with regard to jurisdictional claims in published maps and institutional affiliations. 